\title{
Current markers for infertility in men
}

\author{
Jéssica Alves Magalhães ${ }^{1}$, Larissa Sousa Ribeiro ${ }^{1,2}$, João Paulo Arcelino Rego ${ }^{2}$, Claudia Roberta de Andrade ${ }^{1}$ \\ ${ }^{1}$ Laboratory of Translational Research, Christus University (UNICHRISTUS), Fortaleza, CE, Brazil \\ ${ }^{2}$ Federal University of São Paulo (UNIFESP), São Paulo, SP, Brazil \\ ${ }^{3}$ Federal Institute of Ceará, Boa Viagem Campus (IFCE). Boa Viagem, CE, Brazil
}

\begin{abstract}
Male infertility accounts for about $30 \%$ of the causes of couple infertility and has become a public health concern. Male infertility may be caused by several factors occurring in isolation or association with several complex syndromes. Despite the importance of semen analysis in the initial investigation of infertility, it has been estimated that $15 \%$ of infertile men present normal sperm, a proportion that calls for additional tests to further investigate cases of infertility and accurately determine the factors that alter ejaculate quality. In addition to semen analysis parameters, genetics has been drawing attention. The incorporation of genetic diagnostic methods in the routine practice of andrology laboratories is an important step to further improve assisted reproductive technologies. The present study described the current status of the main methods used in male infertility investigation.
\end{abstract}

Keywords: male infertility, proteomics, semen quality, diagnostic methods

\section{INTRODUCTION}

Fertility is defined as the ability of a couple to establish a clinical pregnancy (Zegers-Hochschild et al., 2017). On the other hand, infertility has been recently considered an important public health problem, characterized by the World Health Organization (WHO) as the failure to attain and maintain pregnancy after twelve months of attempts, without the use of contraceptive methods (Agarwal et al., 2015; revised by Vander Borght \& Wyns, 2018).

One in seven couples in developed countries and one in four couples in developing nations suffer from reproductive infertility. Depending on the region, fertility rates may reach $30 \%$ and affect more than 180 million people, mostly in developing countries (Santoro et al., 2016; Mascarenhas et al., 2012). Men are responsible for $20-30 \%$ of infertility cases, but contribute to $50 \%$ of the general cases, with male infertility affecting about $10 \%$ of couples of reproductive age worldwide and, in many cases, the possibility of treatment (Agarwal et al., 2015).

Infertile males have abnormal spermograms, and etiologies may include environmental, dietary, medical, genetic, and physiological factors (Auger et al., 2001; Kenkel et al., 2001). Male infertility is the result of several factors that may occur in isolation or association with several complex syndromes. The causes may be related to anatomical malformations, gametogenesis dysfunctions, immunological disorders, ejaculatory disorders or acquired through exposure to certain environmental agents (Kuhtz et al., 2014).

The cyclic process of germ cells for sperm formation occurs throughout the life of men, allowing them to be fit for reproduction not only in youth (revised by Sharma et al., 2019). During the life of an individual, gametes undergo important processes of proliferation, differentiation and morphofunctional maturation (Bernabò et al., 2010); spermatozoa acquire progressive motility and the ability to undergo training during transit through the epididymis, with changes resulting from alterations in the composition of the epididymal luminal fluid microenviroment. Sperm maturation begins in the head of the epididymis and follows through the body to the proximal tail, causing intense morphological and biochemical changes to ensure the formation of spermatozoa that are capable of recognizing and fertilizing secondary oocytes in the female reproductive tract, while allowing spermatozoa to acquire progressive motility, potential for survival and success in fertilization (Oh et al., 2006).

Sperm is the male germ cell. It is equipped with a tail, or flagellum, that allows motility; the intermediate piece, where primarily the mitochondria and the head are located, contains the genetic material and the acrosome. The acrosome is formed by the Golgi complex and is constituted of digestive enzymes that facilitate sperm penetration in the oocyte membrane, a fundamental process for fertilization (Fu et al., 2018).

Physicochemical alterations in sperm involve variations of the extracellular medium, from the epididymis and seminal plasma to the secretions of the female reproductive tract, which induce the activation of membrane receptors that lead to the transduction of the intracellular signal (Gadella, 2008). Most of the changes that occur in spermatozoa are mediated by proteins in the fluid of the accessory sexual glands (Austin, 1951; Chang, 1951).

Once completed, the sperm is capable of recognizing, binding and interacting with the oocyte pellucid zone in order to initiate fertilization (Bernabò et al., 2010; Rahman et al., 2013; 2014). These signaling pathways direct the cellular response involving intracellular activation through increased calcium concentration (Boni et al., 2007), change and reorganization of the cytoskeleton (Abou-haila \& Tulsiani, 2009; Barbonetti et al., 2008). The plasma membrane and the outside of the acrosome membrane become more unstable and gradually acquire the ability to merge with each other (Baker et al., 2012; Gadella, 2008; Kwon et al., 2015; Park et al., 2012; 2013; Rahman et al., 2015).

This paper aims to analyze the main current aspects of male infertility research, as well as to describe the main genetic alterations related to infertility and the effects of male age on semen quality.

\section{AGE AND FERTILITY}

In recent years, the postponement of the birth of the first child until the parents have reached ages in which fertility or female reproductive capacity is lower has increased the incidence of age-related infertility. Different factors contribute to this age-related issue in both men and women (Kehlet et al., 2018; Steiner \& Jukic, 2016).

Although female infertility has been the focus of discussions on reproductive aging, a decline in age-related sperm function and consequently male fertility has been shown due to events such as andropause, poorly defined but related to a decline in testicular function, and gradual reductions in testosterone levels each year (McLachlan, 
2000). Sperm parameters, including semen volume, motility and morphology, deteriorate with age, although reductions in sperm concentration have not been observed (Kehlet et al., 2018; Oh et al., 2006).

Some studies evaluated age-related changes in sperm analysis (spermogram), but results have been less than consistent. Environmental factors, chronic diseases and different periods of sexual abstinence are some of the factors that have impaired the selection of individuals for analysis and compromised the conclusions of many studies (Kehlet et al., 2018; Oh et al., 2006).

The impact of age is still a reason for disagreement between studies on semen parameters. Older age has been associated with decreased semen volume (Cavalcante et al., 2008), sperm motility (Colasante et al., 2019), motility and concentration (Dain et al., 2011), volume and motility (Colasante et al., 2019), or all of the parameters above (Colasante et al., 2019).

It has been reported that male age also interferes with the gestational outcomes of couples facing difficulties getting pregnant (Belloc et al., 2008). The outcomes of more than 17,000 artificial insemination procedures were analyzed, and decreases in pregnancy rates of $12.3 \%$ and $9.3 \%$ were observed in men under 30 and men over 45 , respectively. A directly proportional relationship between the occurrence of miscarriage and paternal age was also described (Belloc et al., 2008). Despite divergences in studies on male infertility, results have demonstrated the effects of aging on the male reproductive system. However, the impacts of age-related ejaculate quality decreases on male fertility have not been well established (Cocuzza et al., 2008; Desai et al., 2009).

In the roster of theories that explain human aging, oxidative stress is currently one of the most widely accepted, since a correlation between aging in humans and the oxidative state of the organism has been demonstrated (Gharagozloo et al., 2016; Toocheck et al., 2016; Ammar et al., 2019).

\section{OXIDATIVE STRESS AND SPERM VIABILITY}

Reactive oxygen species (ROS) are important for the physiology, capacity and function of sperm development (Ammar et al., 2019; Agarwal et al., 2006). Superoxide anion, hydroxyl radicals, and peroxide are known byproducts of normal physiological processes, which excessive production results in hydrogen oxidative stress (Gharagozloo et al., 2016).
Oxidative stress is known as a state in which an oxide-generating system is unbalanced with the antioxidant defense system; it has been related to many diseases, including infertility and/or male subfertility (Xavier et al., 2019; Dhawan et al., 2019; Guz et al., 2013).

The effects of significant oxidative stress on motility and the prevention of this phenomenon by adding catalase (Makler et al., 1984) indicated the involvement of oxygen overload in sperm motility. This study described the harmful effects of ROS on sperm function, such as lipid peroxidation and DNA damage, observed in several species.

ROS are produced physiologically to maintain cellular processes such as sperm maturation, capacitation and sperm-oval interaction (De Lamirande \& O'Flaherty, 2008; Rivlin et al., 2004). However, imbalances in ROS production decrease sperm quality via structural modifications in DNA and membrane lipids (Koppers et al., 2008; Irvine et al., 2000; Aitken \& Baker, 2006; Bassiri et al., 2020; Beygi et al., 2020).

On the other hand, ROS are also known to cause significant damage to DNA, both in the mitochondria and in the sperm genome (Aitken \& Curry, 2011; Sawyer et al., 2001). Spermatic DNA lesions are in turn linked to low fertilization rates, impaired embryo development, loss of pregnancy and birth of defective children (Aitken \& Baker, 2006; Quinn et al., 2018; Tarozzi et al., 2007).

\section{FERTILITY AND GENETIC ABNORMALITIES}

In addition to factors related to ejaculate quality, many cases of infertility may be associated with chromosomal anomalies and gene mutations (Tournaye et al., 2017). The human species has relatively common chromosomal abnormalities that result from the loss, gain or abnormal rearrangement of one or more of the 46 chromosomes. Considering these occurrences, there are many molecular and genetic mechanisms involved in reproduction that, when altered, may lead to infertility. Some genetic factors have a clear cause-effect relationship with impaired reproductive function and are part of the diagnosis of infertile males. The factors at play in these cases may be further elucidated with the aid of genetic diagnostics (Tournaye et al., 2017).

Spermatogenesis disorders related to primary testicular damage might manifest as a variety of semen phenotypes, such as azoospermia (absence of sperm in the ejaculate) and oligospermia ( $<15$ million sperm per ejaculate) (Figure 1). Aspermia is a phenotypic manifestation

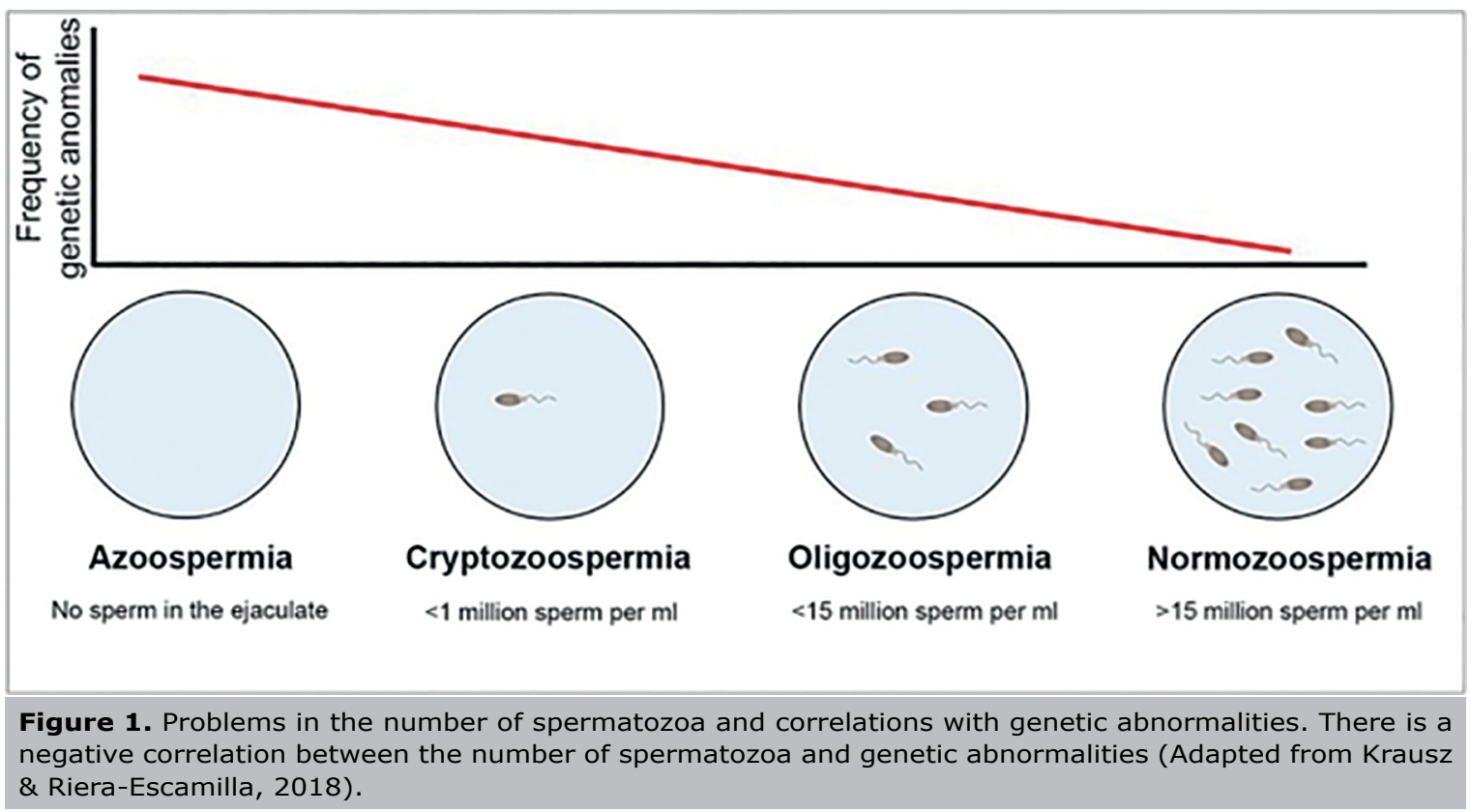


involving different mechanisms, including interruptions in spermatogenesis in one of the stages of the maturation process and hormone level dysfunctions that affect the androgenization process. This clinical heterogeneity implies the involvement of several genetic or acquired factors (Krausz \& Riera-Escamilla, 2018).

In these cases, specific tests are performed to analyze an individual's karyotype through cytogenetics tests performed to study the chromosome structure, its pathologies, functions and properties. Due to technological advances, it is possible to use the banding technique in which the chromosome is individually analyzed to identify and recognize structural abnormalities associated with specific genetic syndromes (Tournaye et al., 2017).

The main genetic alterations that lead to male infertility are chromosomal anomalies, including Klinefelter syndrome and XXY mosaicism; 47, XXY. Genetic mutations such as the ones tied to cystic fibrosis and $Y$ chromosome microdeletions may also occur (Lanfranco et al., 2004).

\section{KLINEFELTER SYNDROME}

Klinefelter syndrome is characterized by hypergonadotropic hypogonadism, low testosterone levels, high FSH and LH levels. Subjects with Klinefelter syndrome are traditionally described as infertile due to lack of ability to complete the spermatogenic process that leads to spermatozoid formation (Aksglaede et al., 2006).

It is characterized by polysomy $X$, with disomy of chromosome $X(47, X X Y)$ as the most frequently observed variant. In $90 \%$ of cases, karyotype $47, X X Y$ appears spontaneously when there is non-disjunction of a pair of $X$ chromosomes during meiosis I or II of parental spermatogenesis. The remaining $10 \%$ present a mosaic form of the syndrome (46XY/47XXY). The $\mathrm{X}$ chromosome comprises about 1100 genes essential to the normal functioning of the testis and brain. Thus, individuals manifest essentially dysfunctions in these two systems (Giudice et al., 2019). Early diagnosis of this syndrome at a younger age is clearly relevant as it might allow preventive cryopreservation of ejaculated or testicular sperm to preserve fertility and the initiation of preventive therapies for associated non-reproductive health problems (Calogero et al., 2017).

Sperm analysis of patients with Klinefelter syndrome or mosaic Klinefelter syndrome, evaluated by in situ hybridization, showed rates of aneuploidy ranging from $2 \%$ to $25 \%$ and $1.5 \%$ to $7.0 \%$, respectively, increasing the probability of passing chromosomal aneuploidies on to the next generations (Kovanci et al., 2001).

\section{Y CHROMOSOME DELETIONS}

The search for $Y$ chromosome microdeletions is performed through molecular tests using the polymerase chain reaction technique. These tests aim to identify the presence of the three AZF regions on the $Y$ chromosome, through probes designed to bind to human DNA and identify the regions of interest (Sen et al., 2004).

The method of in situ hybridization of DNA with fluorescence analysis allows the visualization of numerical alterations directly in the chromosome through a fluorescence microscope that analyzes the sequences of DNA marked with fluorochrome, allowing the analysis of a great number of sperm cells, even if the ejaculate contains few gametes. However, this method permits the analysis of numerical changes only (Rego et al., 2016).

Deletions involving the $Y$ chromosome may impair fertility, with $10 \%$ azoospermia (Stahl et al., 2010). Considered the smallest chromosome in the human genome ( 60 million base pairs), the $Y$ chromosome consists mainly of non-recombinant regions, called male-specific region of the human Y chromosome (MSY) (Lanfranco et al., 2004).
The $Y$ chromosome is essential for male sexual determination, formation and maintenance of germ cells, with its short arm responsible for testicular development and the long arm responsible for factors involved in spermatogenesis (Sen et al., 2004).

Treatments to reduce sperm DNA damage might also reduce the risk of miscarriage and the risk of implantation failure in intracytoplasmic sperm injection cycles (ICSI), also showing less delay in embryo kinetics (Schmid et al., 2007).

\section{SPERM QUALITY AND DNA INTEGRITY}

Correlations between age and sperm DNA damage have been described. A study analyzed 1,125 semen samples for DNA fragmentation. The patients were divided into age groups featuring individuals aged 30 and 45 years, $<30$ years and $>45$ years. The group of men aged 45 years presented higher levels of DNA fragmentation than the other groups (Moskovtsev et al., 2006). As in another study evaluating semen parameters DNA fragmentation, chromatin integrity, genetic mutations and chromosomal abnormalities in 97 men aged between 20 and 80 years, the authors observed a positive correlation between age and level of DNA fragmentation (Wyrobek et al., 2006).

On the other hand, the analysis of semen samples from 140 infertile patients (24-76 years) and 50 men with proven fertility (25-65 years) found no correlation between age and level of DNA fragmentation in any of the groups. To understand these factors, it is important to know the structure of spermatozoa, as well as its process of maturation and training for fertilization (Brahem et al., 2011).

The improvement and wide use of assisted reproductive technologies, especially ICSI, reveals the even greater and more cautious need for the evaluation of sperm nuclear DNA. Spermatozoids with decreased integrity of nuclear DNA, when used to inseminate an egg, may result in fertilization failure or poor prognosis of pregnancy, including early miscarriage. In cases of recurrent miscarriage without an apparent cause, tests to assess the integrity of spermatic DNA chromatin are ordered. This demonstrates that the quality of sperm chromatin plays a fundamental role in the sperm-egg interaction, embryo implantation and division of blastomeres (Piasecka et al., 2006).

\section{SPERM QUALITY DIAGNOSTIC METHODS SPERMOGRAM}

Male fertility analysis was initially required to include an objective evaluation of sperm motility, since there are well-organized protocols showing the lowest standard limits and sperm parameters for ejaculate from normal fertile men (Barták, 1977). The spermogram is one of the main tests used in semen analysis, along with patient interviews to capture life history (Peivandi et al., 2019).

The following parameters are analyzed in a spermogram: volume, viscosity, $\mathrm{pH}$, color and presence of round cells, sperm, mobility, morphology, concentration and vitality. Other complementary, more specific tests include assessment of fragmentation of sperm DNA, in addition to immunological and molecular tests (Clavert et al., 1999).

These tests comprise the basis of couple infertility investigation (Clavert et al., 1999). Diagnosis usually relies on analyses of sperm concentration, motility and morphology, as well as analysis of the whole ejaculate (Peivandi et al., 2019).

Early fact-finding includes running a spermogram and interviewing the patient to unearth history of infections - particularly sexually transmitted diseases, testicular trauma, varicocele, phimosis, impotence, premature ejaculation, malformations, exposure to radiation and chemical agents, preexisting systemic diseases, habits such 
as alcoholism and smoking, and prescribed medications (Peivandi et al., 2019).

\section{SPERM DNA TESTING}

Despite the importance of semen analysis in the initial investigation of infertility, it has been estimated that $15 \%$ of infertile men present normal spermograms, suggesting that complementary and more specific tests are required for a thorough infertility investigation (Aitken et al., 2010).

Tests that evaluate sperm DNA integrity are of great clinical relevance in the investigation of male infertility. DNA fragmentation is routinely analyzed in andrology laboratories, with the following tests ranking as the most cited in literature and widely available in clinics: sperm chromatin structure assay (SCSA); sperm chromatin dispersion (SCD) test; terminal deoxynucleotidyl transferase dUTP nick end labeling (TUNEL) (Fernández et al., 2003; Gorczyca et al., 1993; Larson et al., 2000).

SCSA allows the determination of the proportion of sperm susceptible to DNA fragmentation (Evenson \& Jost, 2000). Since it is carried out in the flow cytometer, this test allows the analysis of a great number of cells (Zarén et al., 2019). The SCD test is based on the principle that spermatozoa with fragmented DNA do not produce the characteristic halo when mixed with agarose. It is a technique described as simple and fast, because it does not rely on the intensity of fluorescence and does not require complex and expensive equipment to be run (Grèze et al., 2019).

The TUNEL assay consists of adding, by means of the terminal deoxynucleotidyl transferase enzyme (TdT), modified nucleotides marked with fluorescent molecules to the fragmented strips. The assay identifies fragmentation in both single and double strands. The technique has high sensitivity and specificity, but is deemed complex and less affordable (La Vignera et al., 2012; Krayevsky et al., 2000).

\section{PROTEOMIC ANALYSIS}

Sperm cells are among the most highly differentiated cells and are made up of a head with a highly compacted chromatin structure and a large flagellum with a central piece that contains the machinery necessary for movement and the paternal genetic and epigenetic material provided to the oocyte. The whole process of sperm differentiation results in a very peculiar protein composition in the mature sperm cell (Thacker et al., 2011).

The evaluation of the protein profile between sperm of different species has revealed different combinations. This variation in protein arrangement confirms that proteins selected from a certain stage of maturation may not be sufficient for diagnosis or prognosis. However, proteomic approaches have been standardized and may be used for subsequent diagnosis of male fertility (Kwon et al., 2017).

Technological advances in proteomics have made it possible to quantify protein abundance and to distinguish the different functions and state of spermatozoa. In the case of maturation of spermatozoa that come out of the testicles, they need to enter in the head of the epididymis for the maturation process to occur and are stored in the tail, thus producing the motility needed for fertilization. Sperm that have not undergone maturation are considered immature and unable to fertilize an oocyte on their own (Belleannee et al., 2011). In such cases, fertilization can only occur with the help of assisted reproductive technologies such as ICSI (Kang et al., 2018) and ejaculated sperm versus aspirated sperm in the epididymis (Dacheux \& Dacheux, 2013).

However, few studies have looked into proteomic modifications in spermatozoa during the functional maturation processes. Sperm chromatin compacting reduces its volume, giving sperm an ergonomic shape that facilitates its journey to the egg, protecting it from genotoxic, physical, and chemical factors while ensuring the integrity of the genome. There is evidence that semen proteins modulate sperm function. Correlations between some proteins and the fertility rate of certain species indicate that they are potential molecular markers of reproductive capacity (Agarwal et al., 2014; du Plessis et al., 2011; Boe-Hansen et al., 2015; Park et al., 2013; Rolland et al., 2013).

\section{OXIDATIVE STRESS ANALYSIS}

Fertility specialists are exploring the diagnosis of stress in sperm to evaluate the possible use of antioxidants to improve sperm quality (Gharagozloo et al., 2016). Semen plasma contains antioxidants needed for fertilization (Atig et al., 2012). Oxidative stress is a condition associated with an increase in the rate of cell damage induced by reactive oxygen species (Wyck et al., 2018).

Excessive generation of ROS was found to induce oxidative damage to the plasma sperm membrane, which then loses its ability to respond to essential calcium signaling in the fertilization process (Aitken et al., 2010). It may be experimentally suggested that if normal spermatozoa were artificially exposed to ROS in vitro, they would lose the ability to fertilize, mimicking the in vivo situation (Aitken \& Baker, 2006).

Antioxidants have been widely used in subfertile males. Several studies have demonstrated that they contribute positively to sperm count, motility and morphology, and help reduce sperm DNA fragmentation (Gharagozloo et al., 2016).

In treatments using ICSI, it is still unclear whether antioxidants help improve pregnancy and birth rates. High quality studies, including different groups of patients, are needed to elucidate the need for antioxidants in ICSI procedures. Oxidative stress has been established as one of the main causes of male infertility and has been often associated with many diseases that cause infertility. In recent years, protein analysis has been used to characterize the protein profiles of the ejaculate of men with different clinical conditions, such as high oxidative stress (Agarwal et al., 2014).

\section{CONCLUSION}

Further studies are needed to define which factors alter the quality of the ejaculate and the specific parameters affected. Delaying fatherhood is an emerging trend, and this new profile has served as a warning for the possible causes of the negative effects of aging on fertility.

With the evolution of assisted reproductive technologies, it is possible to observe even wider multifactorial causes of infertility and different, more specific shades to male factor infertility. In addition to semen parameters, genetics and the anomalies secondary to germ cell mutations have commanded attention. Individuals with somatic chromosomal anomalies, with an atypical number of chromosomes or structural abnormalities, have a higher probability of infertility, repeat miscarriages, and of or having offspring with severe disabilities.

The incorporation of genetic diagnostic methods in the routine practice of andrology laboratories is an important step to further improve assisted reproductive technologies, minimize the adverse effects of gamete manipulation, and optimize results. During the fertility evaluation process of a couple, careful analysis is warranted to identify potential genetic anomalies and ensure accurate genetic counseling.

Different studies have elaborated on the risks associated with decreases in semen quality and fertility introduced by aging. However, due to the diversity of reported results, additional studies examining the relationship between age and semen quality/fertility are needed before definitive conclusions can be drawn. These studies should include 
large populations and apply methodological rigor to improve the reliability of results.

In recent years, proteomic analyses have been used to characterize the protein profiles of the ejaculate of men with different clinical conditions. Recent advances in proteomic techniques, especially in two-dimensional polyacrylamide gel electrophoresis and mass spectrometry, have enhanced the study of spermatozoa and sperm proteins. One of the advantages of gel electrophoresis is that the technique allows the identification of various specific sperm proteins. Proteomics has also provided additional insight into the role of the proteins involved in sperm processes and the differentiation between normal and abnormal states. In addition, studies on sperm proteome demonstrated the importance of post-translational modifications and their ability to cause physiological changes in sperm function. The recent advances in diagnostic techniques may provide information on sperm function and dysfunction and be implemented in human reproduction clinics to identify and characterize the damages that cause male infertility.

\section{CONFLICT OF INTEREST}

The authors have no conflict of interest to declare.

\section{Corresponding author:}

Claudia Roberta de Andrade

Laboratory of Translational Research

Christus University (UNICHRISTUS)

Fortaleza, CE, Brazil.

E-mail: claudiarandrade@gmail.com

\section{REFERENCES}

Abou-haila A, Tulsiani DR. Signal transduction pathways that regulate sperm capacitation and the acrosome reaction. Arch Biochem Biophys. 2009;485:72-81. PMID: 19217882 DOI: $10.1016 /$ j.abb.2009.02.003

Agarwal A, Prabakaran S, Allamaneni SS. Relationship between oxidative stress, varicocele and infertility: a meta-analysis. Reprod Biomed Online. 2006;12:630-3. PMID: 16790111 DOI: $10.1016 / S 1472-6483(10) 61190-X$

Agarwal A, Durairajanayagam D, Halabi J, Peng J, VazquezLevin M. Proteomics, oxidative stress and male infertility. Reprod Biomed Online. 2014;29:32-58. PMID: 24813754 DOI: $10.1016 /$ j.rbmo.2014.02.013

Agarwal A, Mulgund A, Hamada A, Chyatte MR. A unique view on male infertility around the globe. Reprod Biol Endocrinol. 2015;13:37. PMID: 25928197 DOI: 10.1186/ s12958-015-0032-1

Aitken RJ, Baker MA. Oxidative stress, sperm survival and fertility control. Mol Cell Endocrinol. 2006;250:66-9. PMID: 16412557 DOI: $10.1016 /$ j.mce.2005.12.026

Aitken RJ, De Iuliis GN, Finnie JM, Hedges A, McLachlan RI. Analysis of the relationships between oxidative stress, DNA damage and sperm vitality in a patient population: development of diagnostic criteria. Hum Reprod. 2010;25:241526. PMID: 20716559 DOI: 10.1093/humrep/deq214

Aitken RJ, Curry BJ. Redox regulation of human sperm function: from the physiological control of sperm capacitation to the etiology of infertility and DNA damage in the germ line. Antioxid Redox Signal. 2011;14:367-81. PMID: 20522002 DOI: $10.1089 /$ ars.2010.3186
Aksglaede L, Wikström AM, Rajpert-De Meyts E, Dunkel $L$, Skakkebaek NE, Juul A. Natural history of seminiferous tubule degeneration in Klinefelter syndrome. Hum Reprod Update. 2006;12:39-48. PMID: 16172111 DOI: 10.1093/ humupd/dmi039

Ammar O, Houas Z, Mehdi M. The association between iron, calcium, and oxidative stress in seminal plasma and sperm quality. Environ Sci Pollut Res Int. 2019;26:14097105. PMID: 30852746 DOI: 10.1007/s11356-019-04575-7

Atig F, Raffa M, Ali HB, Abdelhamid K, Saad A, Ajina M. Altered antioxidant status and increased lipid per-oxidation in seminal plasma of tunisian infertile men. Int J Biol Sci. 2012;8:139-49. PMID: 22211112 DOI: $10.7150 /$ ijbs.8.139

Auger J, Eustache F, Andersen AG, Irvine DS, Jørgensen N, Skakkebaek NE, Suominen J, Toppari J, Vierula M, Jouannet P. Sperm morphological defects related to environment, lifestyle and medical history of 1001 male partners of pregnant women from four European cities. Hum Reprod. 2001;16:2710-7. PMID: 11726600 DOI: 10.1093/ humrep/16.12.2710

Austin CR. Observations on the penetration of the sperm in the mammalian egg. Aust J Sci Res B. 1951;4:581-96. PMID: 14895481 DOI: $10.1071 / \mathrm{BI} 9510581$

Baker MA, Nixon B, Naumovski N, Aitken RJ. Proteomic insights into the maturation and capacitation of mammalian spermatozoa. Syst Biol Reprod Med. 2012;58:211-7. PMID: 22788533 DOI: 10.3109/19396368.2011.639844

Barbonetti A, Vassallo MR, Cinque B, Antonangelo C, Sciarretta F, Santucci R, D'Angeli A, Francavilla S, Francavilla F. Dynamics of the global tyrosine phosphorylation during capacitation and acquisition of the ability to fuse with oocytes in human spermatozoa. Biol Reprod. 2008;79:649-56. PMID: 18562705 DOI: 10.1095/biolreprod.108.068254

Barták V. Examination of male sterility. Zentralbl Gynakol. 1977;99:1225-30. PMID: 595957

Bassiri F, Nasr-Esfahani MH, Forozanfar M, Tavalaee M. Relationship between Sperm Parameters with Sperm Function Tests in Infertile Men with at Least One Failed Cycle after Intracytoplasmic Sperm Injection Cycle. Int J Fertil Steril. 2020;13:324-9. PMID: 31710194 DOI: 10.22074/ ijfs. 2020.5750

Belleannee C, Belghazi M, Labas V, Teixeira-Gomes AP, Gatti JL, Dacheux JL, Dacheux F. Purification and identification of sperm surface proteins and changes during epididymal maturation. Proteomics. 2011;11:1952-64. PMID: 21472858 DOI: 10.1002/pmic. 201000662

Belloc S, Cohen-Bacrie $P$, Benkhalifa M, Cohen-Bacrie $M$, De Mouzon J, Hazout A, Ménézo Y. Effect of maternal and paternal age on pregnancy and miscarriage rates after intrauterine insemination. Reprod Biomed Online. 2008;17:392-7. PMID: 18765010 DOI: 10.1016/S14726483(10)60223-4

Bernabò N, Mattioli M, Barboni B. The spermatozoa caught in the net: the biological networks to study the male gametes post-ejaculatory life. BMC Syst Biol. 2010;4:87. PMID: 20565893 DOI: 10.1186/1752-0509-4-87 
Beygi Z, Forouhari S, Mahmoudi E, Hayat SMG, Nourimand F. Role of oxidative stress and antioxidant supplementation in Male fertility. Curr Mol Med. 2020. Epub ahead of print PMID: 32867638 DOI: 10.2174/15665240209992008311 23553

Boe-Hansen GB, Rego JP, Crisp JM, Moura AA, Nouwens AS, Li Y, Venus B, Burns BM, McGowan MR. Seminal plasma proteins and their relationship with percentage of morphologically normal sperm in 2-year-old Brahman (Bos indicus) bulls. Anim Reprod Sci. 2015;162:20-30. PMID: 26417650 DOI: 10.1016/j.anireprosci.2015.09.003

Boni R, Gualtieri R, Talevi R, Tosti E. Calcium and other ion dynamics during gamete maturation and fertilization. Theriogenology. 2007;68:S156-64. PMID: 17572483 DOI: $10.1016 / j$.theriogenology.2007.05.048

Brahem S, Mehdi M, Landolsi $H$, Mougou S, Elghezal $H$, Saad A. Semen parameters and sperm DNA fragmentation as causes of recurrent pregnancy loss. Urology. 2011;78:792-6. PMID: 21813165 DOI: 10.1016/j.urology.2011.05.049

Calogero AE, Giagulli VA, Mongioì LM, Triggiani V, Radicioni $A F$, Jannini EA, Pasquali D; Klinefelter ItaliaN Group (KING). Klinefelter syndrome: cardiovascular abnormalities and metabolic disorders. J Endocrinol Invest. 2017;40:705-12. PMID: 28258556 DOI: 10.1007/s40618-017-0619-9

Cavalcante MB, Rocha Mde P, Dias ML, Dias OJ, Souza DO, Roberto IG. Interference of age on semen quality. Rev Bras Ginecol Obstet. 2008;30:561-5. PMID: 19148434 DOI: $10.1590 / \mathrm{S} 0100-72032008001100006$

Chang MC. Fertilizing capacity of spermatozoa deposited into the fallopian tubes. Nature. 1951;168:697-8. PMID: 14882325 DOI: $10.1038 / 168697 b 0$

Clavert A, Bourguignat A, Férard G. The spermogram and the exigencies of quality. Ann Biol Clin (Paris). 1999;57:334-6. PMID: 10377486

Cocuzza M, Athayde KS, Agarwal A, Sharma R, Pagani $R$, Lucon AM, Srougi M, Hallak J. Age-related increase of reactive oxygen species in neat semen in healthy fertile men. Urology. 2008;71:490-4. PMID: 18342194 DOI: 10.1016/j.urology.2007.11.041

Colasante A, Minasi MG, Scarselli F, Casciani V, Zazzaro V, Ruberti A, Greco P, Varricchio MT, Greco E. The aging male: Relationship between male age, sperm quality and sperm DNA damage in an unselected population of 3124 men attending the fertility centre for the first time. Arch Ital Urol Androl. 2019;90:254-9. PMID: 30655635 DOI: 10.4081/ aiua.2018.4.254

Dacheux JL, Dacheux F. New insights into epididymal function in relation to sperm maturation. Reproduction. 2013;147:R27-42. PMID: 24218627 DOI: 10.1530/REP13-0420

Dain L, Auslander R, Dirnfeld M. The effect of paternal age on assisted reproduction outcome. Fertil Steril. 2011;95:18. PMID: 20932518 DOI: 10.1016/j.fertnstert.2010.08.029 de Lamirande E, O'Flaherty C. Sperm activation: role of reactive oxygen species and kinases. Biochim Biophys Acta. 2008;1784:106-15. PMID: 17920343 DOI: $10.1016 / j . b b a-$ pap.2007.08.024

Desai N, Sharma R, Makker K, Sabanegh E, Agarwal A. Physiologic and pathologic levels of reactive oxygen species in neat semen of infertile men. Fertil Steril. 2009;92:1626-31. PMID: 18937945 DOI: $10.1016 / j$.fertnstert.2008.08.109

Dhawan V, Kumar M, Deka D, Malhotra N, Singh N, Dadhwal V, Dada R. Paternal factors and embryonic development: Role in recurrent pregnancy loss. Andrologia. 2019;51:e13171. PMID: 30324700 DOI: $10.1111 /$ and.13171

du Plessis SS, Kashou AH, Benjamin DJ, Yadav SP, Agarwal A. Proteomics: a subcellular look at spermatozoa. Reprod Biol Endocrinol. 2011;9:36. PMID: 21426553 DOI: 10.1186/1477-7827-9-36

Evenson D, Jost L. Sperm chromatin structure assay is useful for fertility assessment. Methods Cell Sci. 2000;22:16989. PMID: 11264952 DOI: 10.1023/A:1009844109023

Fernández JL, Muriel L, Rivero MT, Goyanes V, Vazquez R, Alvarez JG. The sperm chromatin dispersion test: a simple method for the determination of sperm DNA fragmentation. J Androl. 2003;24:59-66. PMID: 12514084 DOI: 10.1002/j.1939-4640.2003.tb02641.x

Fu C, Rojas T, Chin AC, Cheng W, Bernstein IA, Albacarys LK, Wright WW, Snyder SH. Multiple aspects of male germ cell development and interactions with Sertoli cells require inositol hexakisphosphate kinase-1. Sci Rep. 2018;8:7039. PMID: 29728588 DOI: $10.1038 / s 41598-018-25468-8$

Gadella BM. Sperm membrane physiology and relevance for fertilization. Anim Reprod Sci. 2008;107:229-36. PMID: 18556155 DOI: $10.1016 /$ j.anireprosci.2008.05.006

Gharagozloo $P$, Gutiérrez-Adán $A$, Champroux $A$, Noblanc A, Kocer A, Calle A, Pérez-Cerezales S, Pericuesta E, Polhemus A, Moazamian A, Drevet JR, Aitken RJ. A novel antioxidant formulation designed to treat male infertility associated with oxidative stress: promising preclinical evidence from animal models. Hum Reprod. 2016;31:252-62. PMID: 26732620 DOI: 10.1093/humrep/dev302

Giudice MG, Vermeulen M, Wyns C. Blood Testis Barrier and Somatic Cells Impairment in a Series of 35 Adult Klinefelter Syndrome Patients. Int J Mol Sci. 2019;20:5717. PMID: 31739598 DOI: $10.3390 /$ ijms 20225717

Gorczyca W, Traganos F, Jesionowska H, Darzynkiewicz Z. Presence of DNA strand breaks and increased sensitivity of DNA in situ to denaturation in abnormal human sperm cells: analogy to apoptosis of somatic cells. Exp Cell Res. 1993;207:202-5. PMID: 8391465 DOI: 10.1006/excr.1993.1182

Grèze C, Guttmann A, Pons-Rejraji H, Vasson MP, Lornage J, Ouchchane L, Brugnon F. Can the SCD test and terminal uridine nick-end labeling by flow cytometry technique (TUNEL/ FCM) be used interchangeably to measure sperm DNA damage in routine laboratory practice? Basic Clin Androl. 2019;29:17. PMID: 31890218 DOI: 10.1186/s12610-019-0098-2 
Guz J, Gackowski D, Foksinski M, Rozalski R, Zarakowska E, Siomek A, Szpila A, Kotzbach M, Kotzbach R, Olinski R. Comparison of oxidative stress/DNA damage in semen and blood of fertile and infertile men. PLoS One. 2013;8:e68490. PMID: 23874641 DOI: 10.1371/journal. pone. 0068490

Irvine DS, Twigg JP, Gordon EL, Fulton N, Milne PA, Aitken RJ. DNA integrity in human spermatozoa: relationships with semen quality. J Androl. 2000;21:33-44. PMID: 10670517 DOI: $10.1002 / j .1939-4640.2000 . t b 03273 . x$

Kang YN, Hsiao YW, Chen CY, Wu CC. Testicular sperm is superior to ejaculated sperm for ICSI in cryptozoospermia: An update systematic review and meta-analysis. Sci Rep. 2018;8:7874. PMID: 29777145 DOI: 10.1038/s41598018-26280-0

Kehlet SN, Willumsen N, Armbrecht G, Dietzel R, Brix S, Henriksen K, Karsdal MA. Age-related collagen turnover of the interstitial matrix and basement membrane: Implications of age- and sex-dependent remodeling of the extracellular matrix. PLoS One. 2018;13:e0194458. PMID: 29596429 DOI: 10.1371/journal.pone.0194458

Kenkel S, Rolf C, Nieschlag E. Occupational risks for male fertility: an analysis of patients attending a tertiary referral centre. Int J Androl. 2001;24:318-26. PMID: 11737412 DOI: $10.1046 / j .1365-2605.2001 .00304 . x$

Koppers AJ, De Iuliis GN, Finnie JM, McLaughlin EA, Aitken RJ. Significance of mitochondrial reactive oxygen species in the generation of oxidative stress in spermatozoa. J Clin Endocrinol Metab. 2008;93:3199-207. PMID: 18492763 DOI: $10.1210 /$ jc. 2007-2616

Kovanci E, Kovacs T, Moretti E, Vigue L, Bray-Ward P, Ward DC, Huszar G. FISH assessment of aneuploidy frequencies in mature and immature human spermatozoa classified by the absence or presence of cytoplasmic retention. Hum Reprod. 2001;16:1209-17. PMID: 11387294 DOI: 10.1093/ humrep/16.6.1209

Krausz C, Riera-Escamilla A. Genetics of male infertility. Nat Rev Urol. 2018;15:369-84. PMID: 29622783 DOI: $10.1038 / \mathrm{s} 41585-018-0003-3$

Krayevsky AA, Victorova LS, Arzumanov AA, Jasko MV. Terminal deoxynucleotidyl transferase. catalysis of DNA (oligodeoxynucleotide) phosphorylation. Pharmacol Ther. 2000;85:165-73. PMID: 10739871 DOI: 10.1016/S01637258(99)00070-4

Kuhtz J, Schneider E, El Hajj N, Zimmermann L, Fust O, Linek B, Seufert R, Hahn T, Schorsch M, Haaf T. Epigenetic heterogeneity of developmentally important genes in human sperm: implications for assisted reproduction outcome. Epigenetics. 2014;9:1648-58. PMID: 25625849 DOI: $10.4161 / 15592294.2014 .988063$

Kwon WS, Oh SA, Kim YJ, Rahman MS, Park YJ, Pang MG. Proteomic approaches for profiling negative fertility markers in inferior boar spermatozoa. Sci Rep. 2015;5:13821. PMID: 26348888 DOI: 10.1038/srep13821
Kwon WS, Rahman MS, Ryu DY, Khatun A, Pang MG. Comparison of markers predicting litter size in different pig breeds. Andrology. 2017;5:568-77. PMID: 28409901 DOI: 10.1111/andr.12332

La Vignera S, Condorelli R, D'Agata R, Vicari E, Calogero AE. Semen alterations and flow-citometry evaluation in patients with male accessory gland infections. J Endocrinol Invest. 2012;35:219-23. PMID: 21946047 DOI: $10.3275 / 7924$

Lanfranco F, Kamischke A, Zitzmann M, Nieschlag E. Klinefelter's syndrome. Lancet. 2004;364:273-83. PMID: 15262106 DOI: $10.1016 /$ S0140-6736(04)16678-6

Larson KL, DeJonge CJ, Barnes AM, Jost LK, Evenson DP. Sperm chromatin structure assay parameters as predictors of failed pregnancy following assisted reproductive techniques. Hum Reprod. 2000;15:1717-22. PMID: 10920092 DOI: $10.1093 /$ humrep/15.8.1717

Makler A, Fisher M, Murillo O, Laufer N, DeCherney A, Naftolin F. Factors affecting sperm motility. IX. survival of spermatozoa in various biological media and under different gaseous compositions. Fertil Steril. 1984;41:428-32. PMID: 6421626 DOI: 10.1016/S0015-0282(16)47723-X

Mascarenhas MN, Flaxman SR, Boerma T, Vanderpoel S, Stevens GA. National, regional, and global trends in infertility prevalence since 1990: a systematic analysis of 277 health surveys. PLoS Med. 2012;9:e1001356. PMID: 23271957 DOI: 10.1371/journal.pmed.1001356

McLachlan RI. The endocrine control of spermatogenesis. Baillieres Best Pract Res Clin Endocrinol Metab. 2000;14:345-62. PMID: 11097780 DOI: 10.1053/ beem. 2000.0084

Moskovtsev SI, Willis J, Mullen JB. Age-related decline in sperm deoxyribonucleic acid integrity in patients evaluated for male infertility. Fertil Steril. 2006;85:496-9. PMID: 16595239 DOI: $10.1016 /$ j.fertnstert.2005.05.075

Oh J, Lee J, Woo JM, Choi E, Park I, Han C, Baek N, Lee H, $\mathrm{Kim} \mathrm{DH}$, Cho C. Systematic identification and integrative analysis of novel genes expressed specifically or predominantly in mouse epididymis. BMC Genomics. 2006; 7:314. PMID: 17166261 DOI: 10.1186/1471-2164-7-314

Park YJ, Kwon WS, Oh SA, Pang MG. Fertility-related proteomic profiling bull spermatozoa separated by percoll. J Proteome Res. 2012;11:4162-8. PMID: 22794312 DOI: $10.1021 / \mathrm{pr} 300248 \mathrm{~s}$

Park YJ, Kim J, You YA, Pang MG. Proteomic revolution to improve tools for evaluating male fertility in animals. J Proteome Res. 2013;12:4738-47. PMID: 24016215 DOI: $10.1021 / \mathrm{pr} 400639 \mathrm{x}$

Peivandi S, Jafarpour H, Abbaspour M, Ebadi A. Effect of letrozole on spermogram parameters and hormonal profile in infertile men: A clinical trial study. Endocr Regul. 2019;53:2316. PMID: 31734656 DOI: 10.2478/enr-2019-0023 
Piasecka M, Gaczarzewicz D, Laszczyńska M. Evaluation of sperm genomic integrity of normozoospermic men: a prospective study. Folia Histochem Cytobiol. 2006;44:117-22. PMID: 16805137

Quinn MM, Jalalian L, Ribeiro S, Ona K, Demirci U, Cedars MI, Rosen MP. Microfluidic sorting selects sperm for clinical use with reduced DNA damage compared to density gradient centrifugation with swim-up in split semen samples. Hum Reprod. 2018;33:1388-93. PMID: 30007319 DOI: 10.1093/humrep/dey239

Rahman MS, Lee JS, Kwon WS, Pang MG. Sperm proteomics: road to male fertility and contraception. Int J Endocrinol. 2013;2013:360986. PMID: 24363670 DOI: $10.1155 / 2013 / 360986$

Rahman MS, Kwon WS, Pang MG. Calcium influx and male fertility in the context of the sperm proteome: an update. Biomed Res Int. 2014;2014:841615. PMID: 24877140 DOI: $10.1155 / 2014 / 841615$

Rahman MS, Kwon WS, Lee JS, Yoon SJ, Ryu BY, Pang MG. Bisphenol-A affects male fertility via fertility-related proteins in spermatozoa. Sci Rep. 2015;5:9169. PMID: 25772901 DOI: $10.1038 /$ srep09169

Rego JP, Martins JM, Wolf CA, van Tilburg M, Moreno $F$, Monteiro-Moreira AC, Moreira RA, Santos DO, Moura AA. Proteomic analysis of seminal plasma and sperm cells and their associations with semen freezability in Guzerat bulls. J Anim Sci. 2016;94:5308-20. PMID: 28046165 DOI: $10.2527 /$ jas.2016-0811

Rivlin J, Mendel J, Rubinstein S, Etkovitz N, Breitbart H. Role of hydrogen peroxide in sperm capacitation and acrosome reaction. Biol Reprod. 2004;70:518-22. PMID: 14561655 DOI: $10.1095 /$ biolreprod.103.020487

Rolland $A D$, Lavigne $R$, Dauly $C$, Calvel $P$, Kervarrec $C$, Freour T, Evrard B, Rioux-Leclercq N, Auger J, Pineau C. Identification of genital tract markers in the human seminal plasma using an integrative genomics approach. Hum Reprod. 2013;28:199-209. PMID: 23024119 DOI: 10.1093/ humrep/des360

Santoro N, Eisenberg E, Trussell JC, Craig LB, Gracia C, Huang $H$, Alvero R, Casson P, Christman G, Coutifaris C, Diamond $M$, Jin $S$, Legro RS, Robinson RD, Schlaff WD, Zhang $\mathrm{H}$; Reproductive Medicine Network Investigators. Fertility-related quality of life from two RCT cohorts with infertility: unexplained infertility and polycystic ovary syndrome. Hum Reprod. 2016;31:2268-79. PMID: 27402910 DOI: $10.1093 /$ humrep/dew175

Sawyer DE, Roman SD, Aitken RJ. Relative susceptibilities of mitochondrial and nuclear DNA to damage induced by hydrogen peroxide in two mouse germ cell lines. Redox Rep. 2001;6:182-4. PMID: 11523594 DOI: $10.1179 / 135100001101536157$

Schmid TE, Eskenazi B, Baumgartner A, Marchetti F, Young $S$, Weldon R, Anderson D, Wyrobek AJ. The effects of male age on sperm DNA damage in healthy non-smokers. Hum Reprod. 2007;22:180-7. PMID: 17053003 DOI: 10.1093/ humrep/del338
Sen S, Agarwal R, Ambulkar P, Hinduja I, Zaveri K, Gokral J, Pal A, Modi D. Deletion of GOLGA2P3Y but not GOLGA2P2Y is a risk factor for oligozoospermia. Reprod Biomed Online. 2016;32:218-24. PMID: 26655651 DOI: 10.1016/j. rbmo.2015.11.001

Sharma S, Wistuba J, Pock T, Schlatt S, Neuhaus N. Spermatogonial stem cells: updates from specification to clinical relevance. Hum Reprod Update. 2019;25:275-97. PMID: 30810745 DOI: 10.1093/humupd/dmz006

Stahl PJ, Masson P, Mielnik A, Marean MB, Schlegel PN, Paduch DA. A decade of experience emphasizes that testing for $Y$ microdeletions is essential in American men with azoospermia and severe oligozoospermia. Fertil Steril. 2010;94:1753-6. PMID: 19896650 DOI: 10.1016/j.fertnstert.2009.09.006

Steiner AZ, Jukic AM. Impact of female age and nulligravidity on fecundity in an older reproductive age cohort. Fertil Steril. 2016;105:1584-8.e1. PMID: 26953733 DOI: $10.1016 /$ j.fertnstert.2016.02.028

Tarozzi N, Bizzaro D, Flamigni C, Borini A. Clinical relevance of sperm DNA damage in assisted reproduction. Reprod Biomed Online. 2007;14:746-57. PMID: 17579991 DOI: $10.1016 / S 1472-6483(10) 60678-5$

Thacker S, Yadav SP, Sharma RK, Kashou A, Willard B, Zhang D, Agarwal A. Evaluation of sperm proteins in infertile men: a proteomic approach. Fertil Steril. 2011;95:2745-8. PMID: 21536282 DOI: 10.1016/j.fertnstert.2011.03.112

Toocheck C, Clister T, Shupe J, Crum C, Ravindranathan P, Lee TK, Ahn JM, Raj GV, Sukhwani M, Orwig KE, Walker WH. Mouse Spermatogenesis Requires Classical and Nonclassical Testosterone Signaling. Biol Reprod. 2016;94:11. PMID: 26607719 DOI: 10.1095/biolreprod.115.132068

Tournaye $\mathrm{H}$, Krausz C, Oates RD. Novel concepts in the aetiology of male reproductive impairment. Lancet Diabetes Endocrinol. 2017;5:544-53. PMID: 27395771 DOI: $10.1016 / \mathrm{S} 2213-8587(16) 30040-7$

Vander Borght M, Wyns C. Fertility and infertility: Definition and epidemiology. Clin Biochem. 2018;62:2-10. PMID: 29555319 DOI: 10.1016/j.clinbiochem.2018.03.012

Wyck S, Herrera C, Requena CE, Bittner L, Hajkova $\mathrm{P}$, Bollwein H, Santoro R. Oxidative stress in sperm affects the epigenetic reprogramming in early embryonic development. Epigenetics Chromatin. 2018;11:60. PMID: 30333056 DOI: $10.1186 /$ s13072-018-0224-y

Wyrobek AJ, Eskenazi B, Young S, Arnheim N, Tiemann-Boege I, Jabs EW, Glaser RL, Pearson FS, Evenson D. Advancing age has differential effects on DNA damage, chromatin integrity, gene mutations, and aneuploidies in sperm. Proc Natl Acad Sci U S A. 2006;103:9601-6. PMID: 16766665 DOI: $10.1073 /$ pnas. 0506468103

Xavier MJ, Nixon B, Roman SD, Scott RJ, Drevet JR, Aitken RJ. Paternal impacts on development: identification of genomic regions vulnerable to oxidative DNA damage in human spermatozoa. Hum Reprod. 2019;34:1876-90. PMID: 31593593 DOI: 10.1093/humrep/dez153 
Zarén $\mathrm{P}$, Alson $\mathrm{S}$, Henic $\mathrm{E}$, Bungum $\mathrm{M}$, Giwercman A. Interaction between serum levels of Anti-Mullerian Hormone and the degree of sperm DNA fragmentation measured by sperm chromatin structure assay can be a predictor for the outcome of standard in vitro fertilization. PLoS One. 2019;14:e0220909. PMID: 31393936 DOI: 10.1371/journal.pone.0220909
Zegers-Hochschild F, Adamson GD, Dyer S, Racowsky C, de Mouzon J, Sokol R, Rienzi L, Sunde A, Schmidt L, Cooke ID, Simpson JL, van der Poel S. The International Glossary on Infertility and Fertility Care, 2017. Fertil Steril. 2017;108:393-406. PMID: 28760517 DOI: 10.1016/j. fertnstert.2017.06.005 